\title{
KEY ISSUES IN E-PROCUREMENT: PROCUREMENT IMPLEMENTATION AND OPERATION IN THE PUBLIC SECTOR
}

\author{
Simon R. Croom and Alistair Brandon-Jones *
}

\begin{abstract}
This paper presents the analysis from a study into the key lessons learned from e-procurement implementation across a range of UK public sector organisations. The literature relating to e-procurement implementation and operation is reviewed, identifying five main themes addressed by the current literature: impact on cost efficiency; the impact on the form and nature of supplier transaction; e-procurement system implementation; broader IT infrastructure issues; and the behavioural and relational impact of eprocurement. The research carried out was intended to explore the perceptions and reflections of both 'early' and 'late' adopters of e-procurement. Seven key lessons are drawn from the study and presented here. We conclude by proposing areas for further research, including the need for research into failed eprocurement projects.
\end{abstract}

\section{INTRODUCTION}

Electronic procurement systems represent an important development for the purchasing process (Neef, 2001), offering benefits to the organisation through purchase process efficiency gains and price reductions (Croom, 2000; Essig \& Arnold, 2001; de Boer, Harink \& Heijboer, 2002), enhanced collaborative relationships (Holland, 1995;

* Simon R. Croom, Ph.D., FCIPS, Executive Director of the Supply Chain Management Institute, University of San Diego, USA and Alistair BrandonJones Ph.D. candidate, Warwick Business School, University of Warwick, UK. Dr. Croom's teaching and research interests are in supply chain management, e-business and capability development. Alistair Brandon-Jones's research interest is the impact of e-procurement implementation.

Copyright @ 2005 by PrAcademics Press 
Dyer, 2000; Tang, Shee \& Tang, 2001) and significant opportunity for improving the internal service and statues of the purchasing function (Croom, 2000; Osmonbekov, Bello \& Gilliland, 2002; Stanley \& Wisner, 2001; Croom \& Johnston, 2003).

Probably due to the combined influence of the relative 'newness' of e-procurement adoption, the perennial issue of research publication lead times and the limited opportunities to date for longitudinal research, much of the existing e-procurement research has concentrated on the motivations and expectations relating to e-procurement implementation. In this paper we set out to address the need for experience-based research into the operational issues of e-procurement by examining not just the implementation process, but the experiences from public sector eprocurement operation in both local authorities and national civil government departments. An important question that helped shape this research was "what are the actual benefits being achieved from eprocurement?" Our research was conceived initially as an exploratory study and conducted over 18 months across a range of UK public sector bodies.

This paper is structured into four sections. In the first section we examine the current e-procurement and e-business literature in order to review current understanding of the 'e-procurement effect' and to provide a framework for defining what we call transactional structures. The second section briefly describes our research methodology. The third section sets out the seven key lessons from e-procurement implementation across the UK public sector. The final section responds to one of our key findings in order to propose some potential for future research.

\section{THE E-BUSINESS PHENOMENON}

What we now call E-Business arose through the proliferation of the Internet as a platform for inter-organisational systems (IOS) in the late 1990s and has had a particularly significant impact on supply chains and networks. This is not a surprise, for Evans and Wurster's (2000) thesis is that the rise of the Internet has changed the economics of information, giving rise to new forms of affiliation between organisations, of relationship between organisations and of transaction between organisations. Giving specific attention to the implications for supply chain management, Tan (2001) identified potential for improvements in 
supply chain management arising from adoption of e-business systems in four areas:

- Cost performance (from improved productivity and lower input prices),

- Customer service (service quality),

- Process capability (quality consistency),

- Productivity and dependability (from increased control of material flows along the supply chain).

E-procurement is the generic term applied to the use of integrated database systems and wide area (commonly web-based) network communication systems in part or all of the purchasing process. The procurement process encompasses the initial need identification and specification by users, through the search, sourcing and negotiation stage of contracts and order placement and on to include mechanisms that register receipt, trigger payment and support post-supply evaluation.

As Neef (2001) notes, electronic procurement represents a significant and important development in the employment of e-business in supply chain management and in the rest of this paper we will concentrate on the procurement elements of upstream e-business.

\section{EXISTING E-PROCUREMENT RESEARCH}

The following review of the body of literature to date identifies five main themes in e-procurement research relating to the following:

- Cost efficiency benefits;

- The impact of e-procurement systems on the form and nature of supplier governance;

- System implementation;

- Information technology (IT) infrastructure issues; and

- Organisational and relational issues.

Each of these issues will now be examined. 


\section{Cost Efficiencies}

One of the key themes in the existing literature on e-procurement has been concerned with the economies of information (Evans \& Wurster, 2000), in particular the realisation of cost improvements achieved as a result of transactional and process efficiencies. These efficiencies arise through greater opportunity for lower prices from suppliers; from the reduction in process activity needed to complete the total 'requisition to payment' process; through the increased speed of the procurement process and better decision making as a result of improved management information (Min \& Galle, 1999; Croom, 2000; Emiliani, 2000; Zsidisin \& Ellram, 2001; de Boer, Harink \& Heijboer, 2002; Wyld, 2002). The lure of cost efficiencies has been a major catalyst for the adoption of e-procurement (Croom, 2000 ) and it has been widely contended in this body of literature that e-procurement implementation will have considerable implications for the design of the procurement process. However, it was contended by Lancioni, Smith and Olivia (2000) that the precise nature of these process changes was empirically unclear.

Recently, Yen and $\mathrm{Ng}$ (2003) carried out a case study investigation of electronic commerce implementation providing a useful comparison of pre- and post- e-commerce procurement process performance. They support the claims from prior literature that such changes deliver process efficiencies. In addition to the three categories of efficiency improvement mentioned above, they highlighted four additional sources of cost benefit:

- reduction in costs arising as a result of 'digitizing' catalogues,

- reducing errors in order transmission,

- reductions in inventory, and

- reductions in suppliers' marketing costs.

Consequently, improved economies of management information are considered to be a major catalyst for reducing purchase prices through greater transparency of market prices and lower search costs. This observation is supported in the practitioner and general management literature where there is a plethora of anecdotal case evidence to support the view that electronic procurement is a far more efficient and reliable method for the requisition to payment process than preceding manual and semi-automated processes. (For example: Electronic Commerce News, 
2003; Hayward, 2003; Moore, 2003; Parker, 2003; Trommer, 2003; Wheatley, 2003)

\section{Forms of Transactional Structure}

Galliers (1999, pp. 229-230) states that “...with the advent of interorganizational systems, and e-commerce in particular, it is clear that questions of alignment go beyond what we have come to know as the Business - IT alignment issue (e.g. Baets, 1992). It is no longer simply a case of internal alignment alone. Such issues now include alignment with collaborating companies' business and IT strategies (Finnegan et al., 1998) and customer requirements (cf., recent heightened interest in customer relationship management)." In other words, an organisation's deployment of e-business has a significant impact on suppliers' IT and information system (IS) strategies and on the forms of governance, or transactional, structure employed in the supply chain.

How e-procurement may impact supply transactions has been discussed by Holland (1995) and Croom (2001a), both noting that the literature posits two opposing schools of thought. On one side is the view that e-procurement and associated e-business systems will increase the tendency towards arms' length, market forms of transaction because the barriers to entry in electronic transactions are low (Malone, Yates \& Benjamin, 1987; 1989). Indeed, Malone, Yates and Benjamin (1987) argued that the 'electronic brokerage' effects of systems such as eprocurement reduce search costs. Consequently, their view implies that e-procurement adoption would result in a movement away from close, hierarchical relationships to more short-term, market relationships. Barratt and Rosdahl (2002) temper Malone, Yates and Benjamin's position slightly by claiming that ease of search and transparency acts as an advantage to the buyer but may be a disadvantage for the seller. This may, of course, still influence a move towards market-based relationships under e-procurement purely through the attraction to buyers of greater economies in the search process.

In contrast to this view, others have argued that the proprietary nature of certain inter-organisational systems may in fact serve to tie in customers and suppliers to virtual hierarchies or virtual integration (Johnston \& Vitale, 1988; Johnston \& Lawrence, 1988; Konsynski \& McFarlan, 1990). This would be particularly important for e-procurement systems that involve complex data exchange (such as links to customer's production or sales schedules). For example, Brousseau (1990) reviewed 
26 IOS networks, finding that most were used to reduce production or distribution costs and served to reinforce already existing hierarchical relationships among firms. Evans and Wurster (2002) claimed that the low infrastructure and transaction costs of Internet-based systems allowed organizations to exploit the increased opportunities for complex information exchange with multiple partners, but also recognized the value to be gained through closer, hierarchical, relationships between regular trading partners ('affiliation'). Amit and Zott (2001) likewise discussed the importance of close relationships ('lock-in') between trading partners as a key source of advantage to both buyer and seller.

\section{Classifying the Forms of E-Procurement Transactional Structures}

It has been widely recognised in the industrial marketing and purchasing literature that organisations will typically have a range of transactional relationships with their supply base - for example the Robinson, Faris and Wind (1967) 'buyclass' framework distinguished between relationships on the basis of the frequency and variability of the purchased contract. It is our view that it is thus more appropriate to utilise some form of classification of e-procurement governance structures. Thus in Figure 1, we illustrate five contrasting exchange types employed within e-procurement transactions:

\section{Public Web}

Via the public web (Internet) buyers have the opportunity to identify potential suppliers via standard search engines (such as Google.com, Yahoo.com) or specialist trading search engines (such as kellys.co.uk). On-line search and comparison of list prices are typically used for specialist or low value purchases. Depending on the nature of the supplier's web site facility, orders may be placed on-line, via email or through the more traditional route of telephone, fax or mail.

\section{Exchange}

The term 'exchange' here refers to trading sites such as the ebay B2C e-commerce auction site and the B2B auction service provider Free Markets and Synerdeal. These sites allow buyers or sellers to bid for contracts - which in eBay's case simply involves bidding for products offered for sale by private as well as commercial sellers, whilst B2B exchanges provide reverse auction facilities. On-line reverse auctions 
FIGURE1

Classifying E-Procurement Transaction Structures

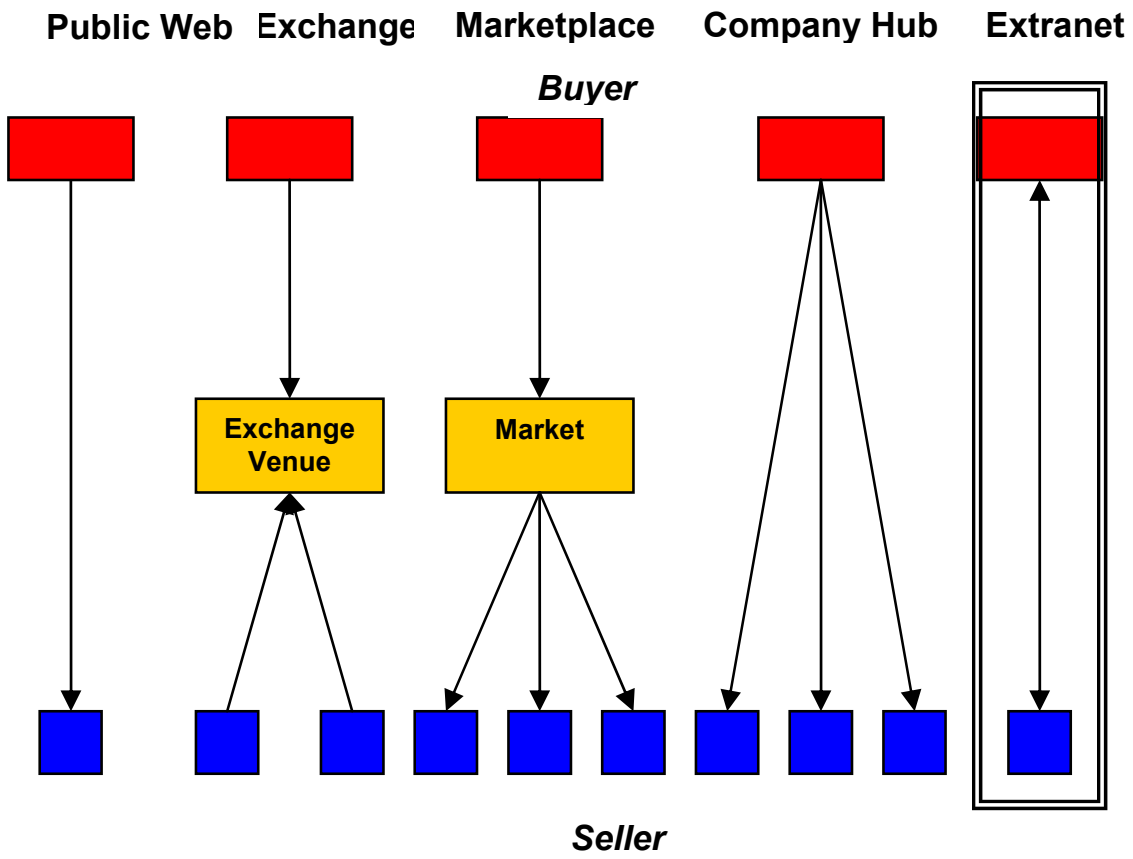

have been extremely successful in reducing purchase prices - our experience has been that typical price savings achieved are around 16\% and such auctions have been used for products as varied as foodstuffs, engineered components and utilities supplies.

\section{Marketplace}

A marketplace is in essence a multi-supplier/multi-products catalogue often hosted and maintained by a third party providing access to users via Internet or LAN connection.

\section{Company $\mathrm{Hub}$}

Often also called a 'buy-side' solution, a company hub is similar to a marketplace since the buyer (rather than a third party) hosts and maintains a multi-supplier/multi-product catalogue. 


\section{Extranet}

An extranet is a secure, often security protected, Internet link between buyer and seller. Such extranets are used primarily for shared and collaborative data - such as delivery scheduling and product design data. Pre-Internet, EDI (electronic data interchange) links represent a type of extranet connection, being dedicated to an individual customer. Although there remain concerns for the security of transmission over the World Wide Web, extranets represents an effective means of communication between close trading partners.

\section{System Implementation}

There have been few detailed empirical studies of e-procurement implementation in the public sector; although in the U.S. Mc Manus (2002) identified expectations of cost and process efficiencies as the primary motivation for public sector implementation. However, she observed that as experience with e-procurement systems has grown, so has considerable debate about some of the fundamental principles behind public sector procurement, including 'lowest bid wins.' In a second, case-based study of Taiwanese military procurement (Liao, Cheng, Liao $\&$ Chen, 2003) the main challenges for e-procurement implementation were found to be the cultural resistance to changes in established procurement processes and practices.

Heijboer (2003) has proposed a framework for the operational implementation or 'roll-out' of e-procurement across the supply base. In his paper, he proposed an analytical model based on the ROI and payback resulting from the e-procurement rollout on a commodity-bycommodity basis. His model proposes that organisations should determine their rollout of e-procurement by aiming for 'quick wins' (or 'harvesting the low hanging fruit').

\section{IT Infrastructure}

Issues concerning information systems development and adoption are central to the e-procurement issue. Rajkumar (2001) identified systems integration as a critical success factor for e-procurement implementation, both with the customer's information infrastructure and in its links to suppliers. In an earlier study, Croom (2001b) surveyed the adoption pattern of IOS. Table 1 sets out the frequency of adoption of the 
TABLE 1

Incidence of E-Procurement System Adoption

\begin{tabular}{|l|l|}
\hline System & Incidence (\%) \\
\hline Email & 85.9 \\
\hline Web Sites & 83.5 \\
\hline Funds Transfer & 83.1 \\
\hline Electronic Data Interchange & 73.5 \\
\hline MS Outlook & 69.9 \\
\hline Lotus Notes & 39.8 \\
\hline Knowledge Sharing & 63.9 \\
\hline E-procurement & 38.6 \\
\hline Intranet & 36.5 \\
\hline Middleware & 37.3 \\
\hline Extranet & 36.5 \\
\hline Portals & 34.9 \\
\hline Global Positioning Systems & 22.9 \\
\hline
\end{tabular}

Source: Croom (2001b).

main forms of web-based and related IS used to support part or much of the procurement process found in this earlier study.

It was not surprising that email, web sites, funds transfer and EDI dominated the list. Email and web sites are dominant and ubiquitous systems, whilst major banks provide support for electronic funds transfer which provides a secure, low cost means of payment. EDI on the other hand is only cost effective for high volume transaction and communication between common trading hierarchies. Often, EDI is deployed for the management of direct supply chains, i.e. for components and materials in manufacturing, or saleable products in retailing. The cost per unit is then relatively low, the benefits of high speed transmission and the sunk cost of investment are all factors which are seen as likely to sustain EDI, or at least integrate it into an InternetEDI structure for the management of specific high frequency exchange supply chains.

In terms of knowledge management nearly two-thirds of respondents employed knowledge sharing systems, which included Microsoft Outlook, Lotus Notes and other systems. Using an existing, and to some degree standardised, package such as Outlook within organisations 
enabled greater communication and coordination in areas of innovation, product development, customer strategies, sourcing, specifying and supply management, and training and development co-ordination.

The use of 'middleware' (i.e. software used to integrate two systems) recognised the challenge of integrating systems, typically with legacy finance systems. At the time of this study $37.3 \%$ of respondents were addressing the challenges of integrating the various elements of procurement systems. Less than $40 \%$ of respondents deployed 'total' eprocurement systems such as Ariba, Peoplesoft or SAP's enterprise buying module.

A recent commercial report by IDC (2003) demonstrated that there remained a slow uptake of e-procurement systems, emphasizing that system infrastructure-related issues such as software integration (including discussion of XML related opportunities) were inhibiting implementation.

\section{Organisational and Relationship Issues}

The adoption of e-procurement can impact on internal and external relational linkages. Internally, the motivation of buyers to use the internet as a resource for various elements of the purchasing process was investigated by Kennedy and Deeter-Schmelz (2001) who concluded that 'organizational characteristics and organizational influences' were significant motivators to the use of e-procurement. In other words, training and relative influence of the purchasing function are key factors influencing the uptake of internet enabled purchasing tools. Also focusing on internal relational linkages, Croom and Johnston (2003) argued that in the context of indirect (MRO) purchases, reduction in 'maverick' or non-compliant buying by users is critical to the achievement of cost and efficiency gains from electronic procurement, contesting that internal customer satisfaction should be a key concern for e-procurement implementation.

Externally, Carr and Smeltzer (2002) found that increased use of information technology between buyer and supplier did not improve levels of trust between buyer and seller, although Ellram and Zsidisin (2002) found that close buyer-supplier relationships had a strong positive impact on the adoption of e-procurement. E-procurement per se could not be considered to deliver improved levels of trust, but it has been found that e-procurement transactions are more likely to be established 
first between close trading partners in high trust relationships (see Malone, Yates \& Benjamin, 1989).

Since longitudinal research is required to fully explore how buyerseller relationships develop under e-procurement, (for example, by adopting an evolutionary approach similar to that of the IMP Group; Ford, Gadde, Hakansson and Snehota, 2003), relatively little literature exists on this topic - although Archer and Yuan (2000) and Croom (2001a) both support the view that increased use of e-procurement and inter-organizational systems will enhance opportunities to build closer and more effective customer-supplier relationships over time.

\section{RESEARCH OBJECTIVES AND METHODOLOGY}

We have seen that the existing e-procurement literature has identified a number of key themes concerning efficiency benefits, governance, systems implementation, IT infrastructure and relational influences. In this research we aimed to contribute to the literature through an exploratory study in two ways - by exploring these themes and by allowing for some inductive analysis of the characteristics of eprocurement system implementation and their operational consequences. To meet our objectives for an exploratory study, our research design used both semi-structured and open questions, thereby allowing respondents to discuss at length their experiences, perceptions and reflections of a range of electronic procurement implementation projects. The research project was funded by a public sector organisation wishing to construct guidelines relating to the main 'lessons learnt' from implementation in the UK public sector as a mechanism for diffusing practice across the sector.

The research participants consisted of adopters of e-procurement; namely seven central government departments, six local authorities and two agencies, whose main role was to offer consultancy and systems support to the public sector.

Initial telephone interviews were semi-structured and typically lasted for one hour. Following the completion of the initial round of interviews, a summary analysis of the findings and pertinent issues was circulated to all participants as the basis for a second round of face to face interviews. In the second round of interviews we utilised semi-structured interviews, in which open questions and participant-identified critical incidents were 
used as the mechanism for identifying the key successes and barriers in each project examined.

All interviews were taped and transcribed verbatim. Coding of all interviews was undertaken by both researchers independently and then cross-compared for final coding.

Across our responding sample, experience of electronic procurement varied. At one extreme, the two Agency bodies had both developed their own e-procurement systems and had over ten year's active involvement with e-procurement. At the other extreme, three bodies had less than twelve month's active operational experience. Of the remaining 10 participating bodies, the modal length of experience was 3 years. (It should be noted that the UK public sector is further supported by a central government department, the Office of Government Commerce OGC - established to support and direct e-procurement and procurement system developments across the whole of civil government in England and Wales. The OGC provides a significant resource in terms of development projects, research knowledge and expertise accessible by all of the respondents).

In the next section of the paper we present the key findings relating to the experiences of our sample respondents from their involvement with e-procurement implementation.

\section{FINDINGS}

Our analysis identified seven key issues arising from the experiences of e-procurement implementation:

\section{External Price Efficiencies}

The main routes for achieving clear accountable cost savings on purchases were through three main mechanisms:

Consolidation of purchase specifications. Through reduction in the variety of alternatives available for users to select, the opportunity to negotiate discounted prices had been a 'significant' benefit. For example, one respondents cited the reduction in the range of writing pens purchased by their department from 47 to 3, reducing the average price per pen from $60 p$ (approx $€ 1$ ) to $45 p$ (approx $€ 0.75$ ). This had also reduced the total quantity of pens purchased per annum due to a combined effect of various reductions on minimum order quantities. 
Reducing the number of suppliers. Improved management information had enabled consolidation of supply to fewer providers and increased user awareness of the 'approved' suppliers for each purchased item.

Improved compliance with existing contracts. The public sector organisations involved in our study all reported that compliance with existing contracts had been one of the major difficulties they had encountered prior to e-procurement implementation. E-procurement adoption had significantly improved compliance due to the ease of access for users to contracted supplies. Only one of the respondents had made participation in the e-procurement system a mandatory requirement for suppliers, but all respondents found that greater accessibility and ease of use were significant catalysts in 'encouraging' users to conform to process.

\section{Internal Cost Efficiencies}

Although savings in terms of purchase expenditure were relatively easy to identify through invoice and budget data, respondents reported significant difficulties in clearly identifying process savings. Whilst the e-procurement literature discussed earlier identifies process efficiencies per transaction as a significant benefit of e-procurement adoption, only one of our participants had been able to validate such savings. One of the agency respondents had commissioned external consultants to conduct a cost analysis of the e-procurement ordering process. The study estimated the cost per order under e-procurement to be $£ 17$ (approx $€ 30$ ), approximately one third of the pre-'e' cost of $£ 60$ (approx $€ 110$ ). However, this cost estimate was considered to be applicable only to a narrow range of standard, high volume, single-source purchases. A number of respondents used the term 'elusive' to describe the realisation of internal cost benefits. One statement that typified a widely held view was that "...we know it's a lot better, but how do you capitalise a saving of just 5\% of a person's time; there may be hundreds of people each saving less than 30 minutes a day."

Implementation rollout. Whilst there was diversity in how long our respondents had been using e-procurement as noted above, we identified only two approaches to the rollout of e-procurement externally (i.e. across the supply base). The most common methodology involved limiting rollout to the organisation's top 5 suppliers. A second cluster of organisations had undertaken a total supply base rollout. There was no 
evidence that the approach adopted was related to the length of time the respondent organisation had been involved with e-procurement. The underpinning logic was primarily related to the overall strategy of the adopter, but the following statements do illustrate the contrasting logic employed:

"..we decided to focus our efforts on the high volume, low value purchases in order to concentrate on achieving the process savings, since that was the basis on which our implementation proposal was made."

"..we needed to demonstrate that we could take control over purchasing and supply, so we were adamant that we should roll this out to all of our suppliers... which involved making ecapability a mandatory requirement for all suppliers."

Problem of the 'tail' of the Pareto distribution of the supply base. Related to the issue of rollout, one of the key concerns expressed by four respondents, but not considered by the remainder, was the challenge of incorporating suppliers with whom they had low expenditures into the eprocurement system. A key determinant in the approach to ' $\mathrm{C}$ ' category suppliers was the marginal cost of adding an additional supplier to the procurement system. One of the central issues in this was the nature of the database employed. We found cases where even large, national, suppliers were unable to readily provide compatible data files for uploading onto some e-procurement catalogue databases. The emergence of common XML standards for database integration were believed to be a potential solution to this problem, but we did not encounter any evidence that this had been realised.

Finance systems integration. Finance systems integration was an important determinant of system selection (when purchasing proprietary e-procurement systems) or system design (if the e-procurement system was to be developed internally). This also had a direct impact on the level of process savings and the nature of the system rollout. All of the large central government departments involved in our study stated that their choice of e-procurement provider had been determined by their current or intended choice of finance system provider. Integration between purchasing and finance systems was seen as the most critical constraint for the selection of system. A breakdown of the systems adopted is provided in Table 2 . 
TABLE 2

E-Procurement and Finance System Characteristics

\begin{tabular}{|l|l|l|l|}
\hline \multicolumn{1}{|c|}{ Department } & \multicolumn{1}{|c|}{ System } & $\begin{array}{c}\text { Finance/ERP Punchout } \\
\text { Process }\end{array}$ & Link to Suppliers \\
\hline Infrastructure 1 & Oracle 11I & Oracle Integrated & Email, fax, mail \\
\hline Treasury 1 & Proprietary & In progress & $\begin{array}{l}\text { EDI. Moving to } \\
\text { web-enabled }\end{array}$ \\
\hline Security 1 & Proprietary & In progress & EDI \\
\hline Security 2 & SAP/ SAP EBP & Payment via BACS & EDI with 6 suppliers \\
\hline Infrastructure 2 & $\begin{array}{l}\text { SAP R/3/ SAP } \\
\text { EBP v2.0c }\end{array}$ & SAP Integrated & Email, fax, mail \\
\hline Infrastructure 3 & Not confirmed & $\begin{array}{l}\text { Only for Logistics } \\
\text { operations: electronic } \\
\text { payment. }\end{array}$ & Email, fax, mail \\
\hline Agency 1 & Proprietary & & Email, fax, mail \\
\hline Agency 2 & Proprietary & $\begin{array}{l}\text { Via Procurement Card } \\
\text { \& XML }\end{array}$ & Email, fax, mail \\
\hline Treasury 2 & Oracle 11I & Oracle Integrated & Email, fax, mail \\
\hline
\end{tabular}

IT infrastructure. The reliability and capability of the organisation's infrastructure (particularly network connectivity) impacted directly on the operational performance of the e-procurement system. In many cases the links to suppliers were not directly over internet but via existing EDI connections, automated fax or mail print out. Details of the infrastructural characteristics are also summarised in Table 2. (It should be noted that the agencies between them also provided all six local authority respondents' systems).

Project management. All of the participants in our study had established project teams to manage the development and implementation process. The team structures reflect two stereotypes: 'open' structures incorporating finance, IT, HR and other operational representatives, and 'closed' structures driven by the IT function (see Clark and Fujimoto, 1991). Our initial conclusions are that the open protocol served to overcome pre-existing 'political' barriers', whilst the closed protocol was most often employed in small scale implementation where internal 'political' barriers were not perceived to be significant. Not surprisingly we found that all of the large, central government departments employed an open protocol since the issue of internal functional power was seen to be a major issue to be addressed in the e-procurement programme. 


\section{CONCLUSIONS}

In our review of the literature we identified seven issues relating to experiences from e-procurement adoption. In issues 1 and 2, significant motivation for e-procurement adoption was considered to be the economic benefits. The possibility of lower prices arising through greater informational economies from the use of e-procurement was discussed by many, including Malone, Yates and Benjamin (1989); Evans and Wurster (2000) and Croom (2000). In our study we found that an important mechanism for realising lower prices was through encouragement for users to comply with existing contracts. Principally this allowed purchasers to provide a more accurate forecast of contract volume requirements to their suppliers, with the concomitant price benefits arising from economies of volume. However, in terms of process cost reductions, these were far more difficult to identify. Only one of the respondents had validated process cost savings at the time of the study and this supported the claims in the literature of a saving of approximately two-thirds on process costs (Croom, 2000).

In issues 3 and 4 we detailed the rollout experiences. This aspect of e-procurement has been examined by Heijboer (2003) who recommended a commodity-based strategy. However, our study respondents adopted a mixed commodity/supplier rollout strategy. Such a strategy recognised the importance of establishing the purchasersupplier connectivity and communications in any rollout programme. This supplier-oriented approach was further emphasised when examination of supply base rollout identified some concerns for integrating low value suppliers in their e-procurement programme.

Issues 5 and 6 , concerning system selection and integration (as illustrated in Table 2), was dominated by e-procurement/finance system integration issues. The ability to 'punch out' procurement order data into financial control systems is regarded as a critical requirement for the success of an e-procurement system and thus close integration with finance systems was identified as an important criteria.

Finally, in issue 7 we examined organisational commitment and support required for e-procurement. One of the key characteristics in achieving organisational support was found to be the structure of the implementation project team - we distinguished between the inclusive, 'open' project team protocol and a more narrow 'closed' protocol, to use Clark and Fujimoto's (1991) terminology. An inclusive project team 
structure was found to allow far greater involvement by the system stakeholders and thus had the consequent benefit of directly addressing any user resistance to e-procurement.

\section{FUTURE RESEARCH}

Our research into e-procurement is ongoing. The study reported has to date attempted to explore the main characteristics of e-procurement adoption and the implementation process. Further research is now being carried out in the UK public sector into user compliance and eprocurement performance in order to validate the prognoses of early commentators. We still feel that e-procurement represents an opportunity for 'revolution' in procurement, but e-procurement per se does not carry a 'cast iron, copper bottomed' guarantee of success. In order to enrich the debate, we feel that one avenue for future research should be to investigate e-procurement failures as a way of furthering our understanding of critical factors for e-procurement performance. A second opportunity for research is to develop means for classification of the different forms of e-procurement, allowing for greater analytical

comparisons between alternative form of electronic purchasing and supply.

\section{REFERENCES}

Amit, R., \& Zott, C. (2001). "Value Creation in e-Business." Strategic Management Journal, 22: 493-520

Archer, N., \& Yuan, Y. (2000). "Managing Business-to-Business Relationships throughout the E-Commerce Procurement Life Cycle." Internet Research: Electronic Networking Applications and Policy, 10 (5): 385-395

Barratt, M., \& Rosdahl, K. (2002). "Exploring Business-to-Business Marketsites." European Journal of Purchasing and Supply Management, 8: 111-122

Brousseau, E. (1990). "Information Technologies and Inter-Firm Relationships: The Spread of Inter-Organizational Telematics Systems and Its Impact on Economic Structure." Paper presented at the International Telecommunications Society, March 18-21, 1990. Venice, Italy. 
Carr, A. S. \& Smeltzer, L. R. (2002). "The Relationship Between Information Technology Use and Buyer-Supplier Relationships: An Exploratory Analysis of the Buying Firm's Perspective." IEEE Transactions on Engineering Management, 49 (3): 293-304

Clark, K. B., \& Fujimoto, T. (1991). Product Development Performance. Strategy, Organisation, and Management in the World Auto Industry. Boston, MA: Harvard Business School Press.

Croom, S. (2000). "The Impact of Web-Based Procurement on the Management of Operating Resources Supply." The Journal of Supply Chain Management, 36 (1): 4-13.

Croom, S. (2001a). "Restructuring Supply Chains through Information Channel Innovation." International Journal of Operations and Production Management,21 (4) pp 504-515.

Croom, S. (2001b). Supply Chain Management in the E-Business Era. Coventry, UK: University of Warwick.

Croom, S., \& Johnston, R. (2003). "E-Service: Enhancing internal customer service through e-procurement." International Journal of Service Industries Management, 14 (5): 539-555

de Boer, L., Harink, J., \& Heijboer, G. (2002). “A Conceptual Model for Assessing the Impact of Electronic Procurement." European Journal of Purchasing and Supply Management, 8 (1): 25-33

Dyer, C. (2000). "B2B Exchange: The Next Step in An Evolving Marketplace.” DSN Retailing Today, 39 (20): 13

"Realizing Rapid Results using eSourcing Tools." (2003). Electronic Commerce News, 8 (13): 1.

Ellram, L. M., \& Zsidisin, G. A. (2002). "Factors That Drive Purchasing and Supply Management's Use of Information Technology." IEEE Transactions on Engineering Management, 49 (3): 269-281

Emiliani, M. L. (2000). "Business-to-Business Online Auctions: Key Issues for Purchasing Process Improvement." Supply Chain Management: An International Journal, 5 (4): 176-186.

Essig, M., \& Arnold, U. (2001). "Electronic Procurement in Supply Chain Management: An Information Economics-Based Analysis of Electronic Markets." Journal of Supply Chain Management, 37 (4): 43-49. 
Evans, P., \& Wurster, T. S. (2000). Blown to Bits. How the New Economics of Information Transforms Strategy. Boston, MA: Harvard Business School Press.

Ford, D., Gadde, L.-E., Hakansson, H., \& Snehota, I. (2003). Managing Business Relationships ( $2^{\text {nd }}$ ed.). Chichester, UK: John Wiley \& Sons.

Galliers, R. D. (1999). "Towards the Integration of E-Business, Knowledge Management and Policy Considerations within an Information Systems Strategy Framework." Journal of Strategic Information Systems, 8 (3): 229-234.

Hayward, C. (2003). Three-year glitch. Financial Management. July/Aug, p 30

Heijboer, G. (2003). "Determining the Optimal Rollout Strategy." In G Heijboer PhD Thesis: Quantitative Analysis of Strategic and Tactical Purchasing Decisions: Electronic Purchasing (pp 162-189). Twente, The Netherlands: Twente University Press.

Holland, C. P. (1995). "Co-Operative Supply Chain Management: The Impact of Inter-Organizational Information Systems." Journal of Strategic Information Systems, 4 (2): 117-133

IDC (2003). Easing into the Tub: Results of the 2002 Procurement Manager Survey. (www.idc.com)

Johnston, R., \& Lawrence, P. R. (1988). "Beyond Vertical Integration: The Rise of Value-Adding Partnership." Harvard Business Review, July/August : 94-101.

Johnston, H. R., \& Vitale, M. R. (1988). "Creating Competitive Advantage with Inter-Organizational Systems." MIS Quarterly, 12 (2): $153-166$

Kennedy, K. N., \& Deeter-Schmelz, D. R. (2001). "Descriptive and Predictive Analyses of Industrial Buyer's Use of Online Information for Purchasing." Journal of Personal Selling \& Sales Management, 21 (4): 279-290.

Konsynski, B. R., \& McFarlan, F. W. (1990). "Information Partnerships: Shared Data, Shared Scale." Harvard Business Review, Sept/Oct: 114-120. 
Lancioni, R., Smith, M. F., \& Olivia, T. A. (2000). "The Role of the Internet in Supply Chain Management." Industrial Marketing Management, 29: 45-56.

Liao, S.-H., Cheng, C.-H., Liao, W.-B., \& Chen, I.-L. (2003). “A WebBased Architecture for Implementing Electronic Procurement in Military Organisations.” Technovation, 23 (6): 521-532

Malone, T., Yates, J., \& Benjamin, R. (1987). "Electronic Markets and Electronic Hierarchies: Effects of Information Technology on Market Structure and Corporate Strategies." Communications of the ACM, 30 (6): 484-497.

Malone, T., Yates, J., \& Benjamin, R. (1989). "The Logic of Electronic Markets." Harvard Business Review, May/June: 166-171.

McManus, S. A. (2002). "Understanding the Incremental Nature of EProcurement Implementation at the State and Local Levels." Journal of Public Procurement, 2 (1): 5-28.

Min, H., \& Galle, W. P. (1999). "Electronic Commerce Usage in Business-to-Business Purchasing." International Journal of Operations and Production Management, 19 (9): 909-921.

Moore, J. (2003). "Manufacturers Struggle with eProcurement, But Still See Gains." Chemical Engineering Progress, 99 (9): 23.

Neef, D. (2001). E-procurement: From Strategy to Implementation. Add Upper Saddle River, NJ: Prentice-Hall/Financial Times.

Osmonbekov, T., Bello, D.C., \& Gilliland, D. I. (2002). "Adoption of Electronic Commerce Tools in Business Procurement: Enhancing Buying Center Structure and Process." Journal of Business and Industrial Marketing, 17 (2): 151-166

Parker, R. (2003). "BA Makes Online Sourcing Mandatory to Save $£ 300$ m." Supply Management, 8 (17): 9.

Robinson, P. J., Faris, C. W., \& Wind, Y. (1967). Industrial Buying and Creative Marketing. Boston, MA: Allyn \& Bacon.

Rajkumar, T. M. (2001). "E-Procurement: Business and Technical Issues." Information Systems Management, 18 (4): 52-60. 
Stanley, L. L., \& Wisner, J. D. (2001). "Service Quality along the Supply Chain: Implications for Purchasing." Journal of Operations Management, 19 (3): 287-306.

Tan, K. C. (2001). "A Framework of Supply Chain Management Literature." European Journal of Purchasing and Supply Management, 7 (4): 39-48.

Tang, J. E., Shee, D., \& Tang, T. (2001). "The Supply-Demand Interaction in Electronic Commerce: A Classification by Type of Relationship and Dominance." Journal of Service Technology and Management, 2 (3-4): pp 289-312

Trommer, D. (2003, November 10). "Learning the ABC'S -- Having Succeeded in Transforming its Procurement Processes for Indirect Materials, Will Ametek Now Consider Doing the Same for Direct Electronic Component Materials?" EBN: 25.

Wheatley, M. (2003). "How to Know If E-Procurement Is Right for You; While Some Companies Have Achieved Price Reductions Through Online Sourcing, the Focus of E-Procurement Initiatives Today Is Process Efficiency. Here's How to Decide If, What and How You Should Buy Electronically." CIO, 16 (17): 1.

Wyld, D. C. (2002). "The Electric Company: How the Supply Chain Is Being Reinvented through the Rapid Application of E-Procurement Processes in the Business-to-Business Arena." Management Research News, 21 (12): 22-23.

Yen, B. P.-C., \& Ng, E. O. S. (2003). "The Impact of Electronic Commerce on Procurement." Journal of Organizational Computing and Electronic Commerce, 13 (3 \& 4): 167-189.

Zsidisin, G. A. \& Ellram, L. M. (2001). "Activities Relating to Purchasing and Supply Management Involvement in Supplier Alliances." International Journal of Physical Distribution and Logistics Management, 31 (9): 629-646. 